\title{
The role of information technologies in lifelong learning development
}

\author{
Svetlana A. Dudko ${ }^{1, *}$ \\ ${ }^{1}$ ISED RAE, Comparative Education Center, 105062, Moscow, Russia
}

\begin{abstract}
The impact of information technologies on the development of lifelong learning in postindustrial (information) society is considered in the paper. Economic progress has caused the need for additional vocational training, reeducation and retraining of employees. The development of computerization and informatization of society has led to radical changes in education. First, adults of post graduate and retirement age, and later the children of preschool age who are actively exploring modern ICT, were involved in a lifelong learning process in developed European countries. The widespread availability of computers and ICT has caused the development of formal, nonformal and informal education. The use of advanced information and telecommunication technologies has led to adjustments in the content and education technologies, helping to solve problems of differentiation and individualization of learning, and the development of variant curriculums. The e-learning began to play a special role.
\end{abstract}

The end of the $20^{\text {th }}$ century was marked by intensive development and implementation of computer and communication technology means in all spheres of our life, emergence of new information technologies and further development of existing ones. As markets become more open, global communications faster and technological change more rapid, the interaction between education and socio-economic conditions are getting closer. Causal relationships of information process and education lie in the fact that higher level of information technology development needs higher education level, and then it becomes a source of further development of science and technology.

Creation of the global information space was an important incentive to changing the classical educational paradigm. One of the topical issues for pedagogics of the $20^{\text {th }}$ century was finding education models adequate to a new stage of civilization. Primarily, permanent education was conceptually seen as continuous postgraduate studies aimed at improvement of knowledge, skills and professional competence. It was all about economic progress that put forward new educational tasks: conversion of traditional professions and creation of new ones made professional education, advanced training and retraining of employees necessary. With the course of time, "Adult Education" had evolved and came to be regarded initially as an independent sphere of educational activity, and then as a subsystem of lifelong learning (LLL) system that interlinks child and adult education in a single process. One of the reasons for switching to LLL was an inclusion of the "new" group - preschoolers - among participants of the integrated educational process. Now the lifelong learning relates to people learning consistently throughout their lifespan, covering all life from the cradle to the grave (J. Smith and A. Spurling, 1999) [1]. The Lifelong Learning concept is considered as a means for preparing a new type of highly qualified personnel, adopting the technological innovations, achieving a competitive and growing economy and for molding of personality, capable to participate in the socio-economic process actively. The purpose of such education is not only a human adaptation to changes in professional activity, but also the continuous development of human personality, inoculation of an appetite for self-education, development of skills to think independently, to acquire new knowledge and exercise judgments.

Educational material became harder and its scope became broader revealing ineffectiveness of the traditional educational system. Thus, the need for innovative technologies emerged. Today's ubiquity of information and computer technology has become an important stimulus for LLL development and improvement in the quality of education. In its turn, this ubiquity has led to changes in the IT infrastructure of the education system. "A Memorandum of Lifelong Learning" (2000) reflects the attitude to LLL as to the main principle of educational activities, ensuring acquisition and preservation competencies and skills necessary for successful functioning in the information society on a high level. The authors of this document considered lifelong learning as a foundation for successful transition of Europeans to life in a knowledge-based society.

The Federal Targeted Program for development of unified educational and information milieu was adopted in Russia in 2001. The objectives of this program include formation of the educational system's IT infrastructure and 
use of information and communication technologies in the educational process. "Information and communication technologies" (ICT) is an umbrella term that describes a variety of devices, mechanisms, methods and algorithms of information processing. A computer equipped with relevant software and telecommunications means with information they provide is an essential modern ICT device [2]. ICT technologies are actively used for data transmitting and a "teacher-student" interaction in present day systems of open and distance education.

It is distance learning that now has become increasingly important for the lifelong learning development. Distance learning (or e-Learning) means the extensive use of information technology: receiving learning materials, consultations and, ultimately, marks occurs by means of computer (for example, using assignments from an electronic textbook recorded on a CD-ROM) or network technologies (using the Internet or a telecommunication technology). Thus, there is no need for a student to attend classes, tests and examinations in educational institution [3]. Due to remote technologies, it is possible to prepare for admission in a university, to get higher education, to learn any foreign language, to take extension or retraining courses, etc. It is of great importance for a modern man who has to learn constantly, has to go onto further study or to retrain, without having enough time for class attendance. It is also important that students are given the opportunity to work at an appropriate pace.

It puts forward two models of lifelong e-learning. One of which reflects employees' approaches to their own elearning and self development, the employee model. The other model reflects the motivations of employers in promoting lifelong e-learning opportunities, by way of engagement in e-learning courses, to their staff in order to improve the organization's effectiveness, the employer model [4]. The goal of the first model is the use of elearning by employees to improve their current or future employment prospects. The concept of this model is as follows: under the influence of the motivation for selfdevelopment, provided access to educational opportunities through e-learning, employees may stay in the profession and improve their professional skills or tread a new ground. At that lifelong learning can be funded by government institutions, employers, or by students themselves. The second model implies that lifelong elearning is used by employers as a way of improving their organizational performance. In this case acquirable profit is organizational to a greater extent, as a result of some compromise: the employer gets highly skilled workforce by providing their employees the possibility of the lifelong distance learning as long as the labor agreement is in effect. This surely affects positively on the performance and competitiveness of company.

The following information technologies are used in distance learning: sending of the studied material by computer telecommunications; debates and seminars conducted via computer communications; videotapes; national/regional television and radio broadcast of learning programs; cable TV; voice mail; bilateral video and teleconferences; unilateral video broadcast with feedback by phone; electronic (computer) educational resources.
Distance learning programs cover a wide range of professions. The doubtless advantage of such programs consists in the fact that the student himself defines speed and level of an education. Alongside, distance learning plays an important role in education of disabled people, special needs and gifted children. There is an individualization of the learning process based on the programs that take into account not only the interests, but also the possibilities of students and teachers. Distance learning is often used with a shortage of teachers, when one teacher is forced to serve a number of schools. Distance learning mode, where the choice of methods, tools and learning pace reflects the individual differences of students and their potential physical abilities, has become a real salvation for many children and adults, and a breakthrough in training.

The development of IT and telecommunications has created a basis for implementation of scientific and educational programs in the entire chain of lifelong learning at a qualitatively new level. The European Parliament Resolution (2008) was of great importance for European schools. It declared implementation of media education to be mandatory in all schools of the European Union. Under "media education", teaching of theory and practical skills for mastering of modern means of mass communication is understood which is regarded as a part of the specific autonomous scope of knowledge in the pedagogic theory and practice. It should be distinguished from the use of media as aids in the teaching of other areas of knowledge, such as, for example, mathematics, physics or geography (UNESCO, 1984).

In EU countries multimedia means of learning and information technologies are used in almost all disciplines at schools. For example, it is clarified on the website of the Ministry of National Education of France that in high school IT-technologies are used for data retrieval and text processing during the lessons in the first language; for map, image and other digital information resources processing during history and geography lessons; software involved in the mathematics and natural science lessons (for example, when studying the earthquake phenomena); during the lessons in the second language students learn to work independently through multimedia; during art classes they learn to work with digital tools of visual design, at music lessons - with tone generators, etc. Learning of computer literacy and foreign language using ICT introduced in the curricula of pre-school institutions [5]. In high school there is an opportunity to get additional diploma in information technology (e.g., B2i diploma).

Media education plays an important role in Russia too. Several media education websites, including the site on the federal portal of the Ministry of Education and Science of the Russian Federation, are created and maintained (URL: http://edu.of.ru/mediaeducation). Since January 2005, the Russian pedagogical journal "Media Education" has been issued (URL: http://www.mediagram.ru/mediaed/journal/). The notion of "Multimedia" and "Means of Multimedia" is closely related to computer processing and performance of heterogeneous information on the one hand and on the other hand, it is at the core of the ICT tools functioning, that significantly affect the efficiency of the educational process [6]. The use of multimedia at lessons can be 
described as the representation of objects and processes with the help of photos, video, graphics, animation, and sound. Russian teachers speak positively about the impact of multimedia technologies on the quality of education for people of different ages: from preschoolers to the elderly. Multimedia programs provide information in various forms and thus make the learning process more effective. Besides information density of multimedia environment is much higher. For example, one page of text contains about 2 Kbytes of information. A teacher takes a few minutes for the pronouncement of this text. While a full screen video brings about 1.8 Gbytes of information per minute. Saving of time needed to study the specific material in this case is an average of $30 \%$, and gained knowledge is stored in the memory much longer. It is necessary to add a lot of positive psycho-physiological factors just to numeracy [7].

In 1960s, when audiovisual teaching methods were actively used in education, G.M. McLuhan, a Canadian philosopher and philologist, wrote that the audiovisual era restores the sensing balance, disturbed by the oral and visual culture types, by distributing loads between sight and hearing in a more uniform and "physiological" manner, as well as allows a person to be in the center of events and to respond to them in a natural emotional way [8]. But very soon, it became clear that the new information technologies have led to both positive and negative consequences. W. J. Martin, an Irish scientist, pointed to a number of changes caused by information technologies: increased awareness of information and information technologies; growing awareness of computer literacy; wide occurrence of computers and information technology; development of computerization and IT penetration in society and education; government support for the development of microelectronics and computer technology and telecommunications; propagation of computer viruses and malicious programs around the world [9].

It is extremely important that the emergence of new information technologies radically changes the process of human thinking. Due to the different content of the information, both positive and negative kinds, as well as the specific form of its presentation, the problem of ethics, reliability of information, the impact on the psyche and the subconscious of pupils, etc. are being revealed. The format of modern communication media offers information in the form of short blocks - news, films and broadcasts fragments interrupted by advertising. A. Toffler, an American philosopher, sociologist and futurologist, designated this new type of culture as a "blip culture". In this, "instead of receiving long, related 'strings' of ideas, organized or synthesized for us, we are increasingly exposed to short, modular blips of information - adverts, commands, theories, shreds of news..." [10]. He considered the blip-culture as a component of the information culture. And he sees a positive development in this specification of thinking: the ability to perceive vast arrays of information and of growing data streams is generated. In such circumstances the transition to a new type of an information adapted personality becomes a reality which is inevitable in the modern situation. The main characteristics of such personality are a natural inclusion in the information processes, ability to literal perception of information received and aiming for its efficient use (Toffler, 1980).

A man of this new information culture strives to create its own material from the mosaic of information. This form of perception is formed like "zapping", when new image, made up of information fragments and shards of memories, is creating by non-stop switching-over TV channels. This image does not require imagination, reflection or thinking, as the "reboot" and "update" of information takes place here all the time [11].

The life of adults in the intensive information environment and the influence of mass-media and Internet on children and teenagers are subjects for study in all countries. Previously researchers were able to consider changes in the dynamics; now they are barely keeping up with events. The information environment is changing faster than means of its analysis. It should be added that information provided by cyberspace or TV is not always science-based, commonly it is aimed at manipulation of the user consciousness. It is possible to find almost any information in Internet, but at the same time there is a risk for spreading of "false or inaccurate statements, fraud and other negative phenomena" around the world [12]. On the other hand, thanks to Internet "education all over the world becomes an open system, there is an active interaction of different local paradigms of education, different value systems, contents and forms of socialization and teaching process organization. Internet is becoming an essential way of all possible competencies formation, a source of global civic education. Under the conditions of globalizing educational environment, Internet, mass media and other digital technologies are considered as main social institution reforming the world of education", - writes I. Tagunova, professor of the Russian Academy of Education [13].

In the post-industrial society, the information culture becomes not so much a set of applied knowledge (use of media libraries, networks) but a specific criterion for personality development that characterizes dialogism of perception, variability and knowledge system openness [14]. Educational level and qualification, learning capability, creativeness and ability to think outside the box are the most valuable qualities of the employee.

Adoption of new information technologies becomes necessary for all citizens in their daily lives. It is noteworthy that this is typical not only for that sphere of human activity, which is formed as a result of the development of new technologies, but also for the specialties that a couple of decades ago suggested to be of low qualification. A large category of people far from school or even college age is added to the traditional school-age population. Thus, the forecast of Japanese philosopher and futurologist E. Masuda works well. He said that in the information society great attention will be paid to adult and elderly education and that it will help them to adjust to rapid changes in society and to develop their knowledge and skills (Masuda, 1981) [15]. It is a complex, long-term and expensive process, however, it is much cheaper than subsidizing of the permanent unemployed people [16]. Prime Minister Margaret Thatcher was guided by the same principle, saving the economy of Britain in the late 1970s. The coal industry 
which has become totally unprofitable at the time was virtually destroyed; a lot of coal mines were closed down and thousands of workers laid off. Figuratively speaking, she gave them a fish-rod instead of fish. Particularly for laid-off workers, dozens of retraining and reeducating courses have been opened, and then many of those people found work in other industries successfully. (Certainly, it did not prevent them from hating "Iron Lady" deeply for the rest of their lives). Here is one example of how the scientific and technological progress and new technology affect the development of lifelong learning.

The dynamism of modern civilization, which has allowed many countries to give impressive results in economic development, has led to the emergence of a number of social problems caused by the population aging, unemployment, poverty and marginalization of certain sections of society. A crucial factor for their decision was the lifelong learning, including the adult education subsystem. Medicine and public health success, development of social protection and pension systems contributed to the increase of a lifetime of people in the developed world. This phenomenon called into being two problems closely related to each other: 1) the need for greater use of the creative possibilities and professional experience of the elderly; 2) creating conditions for vitality and sense of self-importance preserving for people in this age group. The development of computer education system has created opportunities for introduction of active elderly citizens to new information technologies. It reduces social exclusion even of those who cannot come out for health reasons. Professional geriatric rehabilitation of the elderly includes such aspects as the preservation of the ability to work as long as possible, the organization of retraining and training systems for elderly and old people on the basis of the rehabilitation centers, the provision of jobs and greater involvement of pensioners in socially meaningful activities. The elderly people are happy to join the ranks of participants in a lifelong learning process. Various forms of additional andragogical training are becoming widely used.

New information technologies contributed to the further development of lifelong learning, including the form of so-called "women's education". Scientific and technological progress has brought facilitation of domestic life, and new information and communication technologies allow women to join the new social and economic realities quickly and to assess their potential for further education or self-education in the changed circumstances. When children have grown up, and woman is in her forties, she has a huge potential for self-realization. And women have become more actively involved in the economic, social and political life of society. They start to master new professions. Many extension and retraining courses are now focused on the needs of women. Nowadays the use of advanced information and communications technology allows the majority of women in European countries return to work shortly after delivery, combining child-rearing with paid work. That gives them greater independence in path of life choosing.

In other words, thanks to scientific and technological progress and the development of information technologies a boom of formal, non-formal and informal education has started in the late twentieth and early twenty-first century.
The practical issue for the acquisition of knowledge, skills and skill conversion, rather than diploma comes to the fore. The use of the latest ICT allows one to solve issues of differentiation and individualization of education; development of variant forms, methods, techniques and means for implementation of educational programs; creation of different models of specialized and compensatory education, taking into account the individual needs and possibilities of students of different ages. The continuous learning process, aimed at the mastery of new knowledge and skills of its application is the central, backbone characteristic of the information economy.

It should be noted that with the development of the information economy, its social-oriented nature has greatly enhanced. It is necessary to increase investment in people significantly, in order to use the possibility of the person in the labor market. Now the main purpose of education largely is to ensure the conditions for human development, opportunities for self-realization and self-learning throughout life. In other words, education is at the center of modern civilizational changes.

\section{References}

1. J. Smith and A. Spurling, Lifelong Learning: Riding the Tiger (Cassell, London, 1999)

2. Information and communication technologies in education. Available online: URL http://www.ict.edu.ru (accessed 04.02.2016) [In Rus]

3. I. Elkina, Otechestvennaya i Zarubezhnaya Pedagoguika, 6 (2013) [In Rus]

4. J. Simmons, E-learning and earning. The impact of lifelong e-learning on organisational development. Available online: URL http://www.hope.ac.uk. (accessed 13.11.2015)

5. Website of the Ministry of National Education of France. Available online: URL http://www.education.gouv.fr/cid81/page.html/ (accessed 04.02.2016)

6. Information technologies in education. Available online: URL http://physics.herzen.spb.ru/teaching/materials/gose $\mathrm{xam} / \mathrm{b} 25 . \mathrm{htm}$ (accessed 04.02.2016)

7. D. Zhdanov, Polzunovskii Almanakh, 3 (2007) [In Rus]

8. M. McLuhan, Understanding Media: The Extensions of Man (N.Y.: McGraw Hill, 1964)

9. W.I. Martin, The Information Society (London, 1988)

10. A. Toffler, The Third Wave (William Morrow and Co, New York, 1980)

11. A. Kostina, Tendencies of Information Society Culture Development: Analysis of Contemporary Information and Postindustrial Conceptions. (Information Humanitarian Portal "Knowledge. Understanding. Skill", No. 4, 2009). Available online: URL http://www.zpu-journal.ru/ezpu/2009/4/Kostina_Information_Society/ (accessed 02.03.2016) [In Rus]

12. E. Yakushina, Media education: how to learn to work with information properly (Global Online 
Magazine MIC. No. 3, 2012). Available online: URL http://mic.org.ru/3-nomer-2012 (accessed 02.03.2016) [In Rus]

13. I. Tagunova, Otechestvennaya i Zarubezhnaya Pedagoguika 1 (2011) [In Rus]

14. E. Bondarenko, "Education Network", 1 (2013)

15. Y. Masuda, The Information Society as PostIndustrial Society (World Future Society, 1981) [In Rus]

16. A. Toffler, Previews \& Premises (William Morrow \& Co, New York, 1983) 